\title{
Projeto Pádel Cidadão: possibilidades no processo formativo de acadêmicos de educação física e aprendizagem para alunos da educação básica
}

\author{
physical education course and elementary public school \\ Mariza de Fátima dos Santos Sanchez, Lucia Helena Rivero Meza, \\ Phillip Vilanova Ilha, Fernanda Stein \\ Universidade Federal do Pampa (Unipampa), Uruguaiana/RS, Brasil
}

Citizen Paddle Project: prividing an experience with racket sport to students from

\section{HISTÓRICO DO ARTIGO \\ Recebido: 18 abril 2020 \\ Revisado: 17 julho 2020 \\ Aprovado: 21 junho 2020}

\section{PALAVRAS-CHAVE:}

Educação física; Esporte com Raquete; Pádel.

\section{KEYWORDS:}

Physical Education; Racket Sport; Paddle.

\section{RESUMO}

INTRODUÇÃO: O Pádel é um esporte de raquete que, no Brasil, começou a ser difundido pelo Sul, trazido por argentinos e uruguaios no final da década de 80 . Ele faz parte da cultura corporal, entretanto pouco presente na formação inicial dos acadêmicos e como conteúdo das aulas de Educação Física.

OBJETIVO: Relatar a experiência do Projeto Pádel Cidadão, que tem com objetivos proporcionar o conhecimento e a vivência da modalidade esportiva de Pádel aos acadêmicos do curso de Educação Física - Licenciatura da Universidade Federal do Pampa e oportunizar a vivência do Pádel a estudantes do ensino fundamental da rede pública do município de Uruguaiana (RS).

MÉTODOS: Estabelecemos parceria entre a Unipampa e um complexo esportivo de Pádel do município de Uruguaiana, que emprestou as quadras duas vezes na semana, visto que o Pádel requer espaço e materiais específicos. O projeto foi desenvolvido no período de julho a dezembro de 2019 e dividido em duas ações: 1. Encontros semanais com discentes do curso de Educação Física; 2. Encontros semanais com estudantes da rede pública de ensino de Uruguaiana. Participaram 10 estudantes de Educação Física, 2 Técnicos Administrativos, 2 docentes e 19 alunos do 5o ano do ensino fundamental.

RESULTADOS: Identificamos que os estudantes envolvidos permaneceram motivados e demonstraram interesse pela vivência do Pádel. A partir dessa experiência, os graduandos puderam refletir sobre formas de sistematização e metodologias possíveis para o seu desenvolvimento em diferentes âmbitos de atuação profissional. Também, os alunos do ensino fundamental tiveram a oportunidade de vivenciar uma modalidade pouco explorada nas aulas de Educação Física e que poucos teriam acesso.

CONCLUSÃO: O Projeto Pádel Cidadão tornou-se espaço/tempo de formação profissional para além da grade curricular, articulando o labor intelectual, motor, manual e vivências. Além disso, há grande interesse das crianças em aprender novos esportes com raquete.

\section{ABSTRACT}

BACKGROUND: Paddle is sport, which use a racket to play. This physical entertainment spread in South America, mainly in Argentina and Uruguay, in the last decade of 1980. Even though it is a contemporaneous sport in their culture, it does not be included in the academic curriculum of the physical education course.

OBJECTIVE: Contextualizing this situation and overcoming the lack in the academy program of paddle education, this work had the aim to notify the impact of Citizen Paddle Project experience during physical education classes on Federal University of Pampa. This project provided not only the knowledge and familiarity with paddle in the academic environment, but also the opportunity of students from the elementary public education of Uruguaiana city to practice this sport.

METHODS: The courts were provided by the Engenho Paddle Sport Center twice a week during July to December of 2019. The project consisted in the weekly meeting with students of the Physical Education course at the University; and separately, with students of elementary public school. The project involved students from Physical Education course (10), and 5th grade of elementary school (19); administrative technicians (2); and professors (2).

RESULTS: It was possible to observe the interest and motivation of students during the paddle project. Through this experience, the academic students could reflect on the new systematization and methodologies that could facilitate the application of paddle education in their professional area. In addition, the elementary school students had the opportunity to experience this modality, which is still unexplored in their physical education classes.

CONCLUSION: Citizen Paddle Project impacted greatly both academic and elementary students. It created an environment with new possibilities in the professional qualification of physical educator. Moreover, it was improved the intellectual and motor skills of students by the development of paddle abilities. 


\section{INTRODUÇÃO}

O Pádel é uma modalidade esportiva de raquete que teve sua origem derivada do jogo de tênis. De acordo com a Confederação Brasileira de Pádel (COBRAPA, 2017), o jogo surgiu no interior de navios ingleses, por volta de 1890 , como forma de adaptação do jogo de tênis ao ambiente interno dos navios, onde os praticantes usavam paredes para que a bola não caísse no mar. O esporte, até então conhecido como "tênis de alto mar", popularizou-se e passou a ser praticado em terra firme na Europa.

Na América do Sul, o Pádel chegou a partir da influência espanhola, especialmente na Argentina e no Uruguai. Logo, este esporte atravessou fronteiras e começou a ser praticado, na região Sul do Brasil, trazido pelos uruguaios e argentinos (COBRAPA, 2017). Atualmente ele é praticado em todo o país, porém é possível identificá-lo com grande expressividade em cidades fronteiriças do sul, a exemplo do município de Uruguaiana - Rio Grande do Sul (RS). Hoje, o Pádel é parte da cultura esportiva do RS.

Embora expressivo nas regiões da Campanha e Fronteira Oeste do estado, o Pádel, assim como outros esportes com raquete, são poucos explorados enquanto conteúdo e nos currículos dos cursos de graduação de Educação Física (SILVA et al., 2017). No âmbito da Educação Física escolar, existe ainda na realidade brasileira a hegemonia do trabalho com esportes considerados tradicionais (voleibol, futebol, basquetebol e handebol) em detrimento de outras modalidades que fazem parte do repertório de manifestações da cultura corporal em um dado contexto, como por exemplo os esportes com raquete (ROSÁRIO; DARIDO, 2005).

De acordo com Silva et al. (2017), além das justificativas como a falta de materiais e espaços apropriados para a prática, existe ainda a compreensão de esportes com raquete que limita-se ao ensino do Tênis de Campo, que historicamente está associado a uma prática esportiva elitizada, com acesso restrito a um determinado grupo social. Ainda sobre a inserção dos esportes com raquete nas aulas de Educação Física escolar, Corrêa, Freitas e Silva (2019), identificaram que os professores sentem-se despreparados para o trabalho com este conteúdo, já que o ensino-aprendizado nas aulas ainda está pautado no esporte de rendimento, institucionalizado.

Entretanto, dentro de uma perspectiva crítica da Educação Física, os autores Silva et al. (2017), Corrêa, Freitas e Silva (2019) alertam para a necessidade de questionar tais argumentos e refletir sobre propostas alternativas de vivência, sistematização, organização do conteúdo, de materiais e de espaços, além de ampliar o olhar para outras modalidades esportivas de raquete.

É neste contexto que se insere o Projeto Pádel Cidadão, construído a partir da necessidade de criação de um tempo/espaço pedagógico de formação acadêmica e de troca de conhecimento e aprendizagem com a comunidade escolar do município de Uruguaiana. Assim, o objetivo deste artigo é relatar a experiência de seis meses do projeto Pádel Cidadão, o qual possui dois principais objetivos: 1) proporcionar o conhecimento e a vivência da modalidade esportiva de Pádel aos acadêmicos do curso de Educação Física - Licenciatura, da Universidade Federal do Pampa; e 2) oportunizar o conhecimento e a vivência da moda- lidade esportiva de Pádel a estudantes do ensino fundamental da rede pública do município de Uruguaiana (RS), bem como a promoção do esporte educacional e de lazer.

\section{MÉTODOS}

O presente trabalho trata-se de um relato de experiência de atividades de ensino e extensão do projeto Pádel Cidadão realizado entre os meses de julho a dezembro de 2019, que foi desenvolvido junto ao Grupo de Estudos em Educação Física e Esportes (GEEFE), da Universidade Federal do Pampa (Unipampa), campus Uruguaiana.

Inicialmente, para realização do projeto Pádel Cidadão, firmamos uma parceria entre a Unipampa e um complexo esportivo de Pádel do município de Uruguaiana (RS), que cedeu a quadra duas vezes por semana (quarta-feira e sexta-feira), das $11 \mathrm{~h}$ às $12 \mathrm{~h}$. A parceria foi estabelecida, pois o jogo de Pádel requer espaço e materiais específicos para a sua prática (campo retangular que mede $10 \mathrm{~m}$ de largura por $20 \mathrm{~m}$ de comprimento, dividido por uma rede com $90 \mathrm{~cm}$ de altura, com paredes de até 4 $\mathrm{m}$ ao fundo e parte das laterais da quadra; a bola é de borracha semelhante à de tênis, com superfície uniforme; a raquete é feita com fibras de carbono), conforme Figuras $1 \mathrm{~A}$ e $1 \mathrm{~B}$.
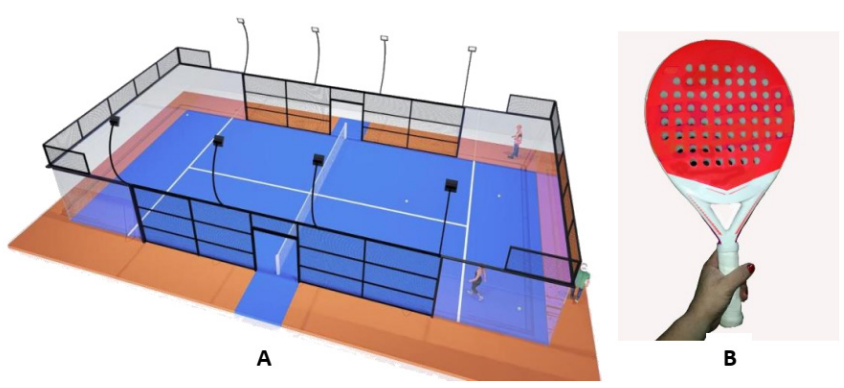

Figura 1. Quadra de pádel (A) e raquete de pádel (B). Fonte: Os autores, 2020.

O projeto foi dividido em duas grandes ações:

1. Com enfoque no ensino de acadêmicos. Com encontros semanais ofertados para os discentes do curso de Educação Física - Licenciatura, da Unipampa, com duração de uma hora, para a vivência e o desenvolvimento dos conhecimentos práticos e didático-metodológicos da modalidade Pádel. Os encontros aconteceram nas quartas-feiras e foram mediados por uma graduanda em Educação Física com conhecimentos e experiência na modalidade e sob a coordenação de dois professores do curso. Fizeram parte dos encontros dez graduandos em Educação Física, dois Técnicos Administrativos e dois professores coordenadores. Na medida em que os graduandos em Educação Física adquiriam conhecimentos didático pedagógicos, participavam também como monitores dos encontros com os alunos da rede pública de ensino do município.

2. Com enfoque na extensão universitária. Com encontros semanais, nas sextas-feiras, oferecidos para estudantes da rede pública de ensino do município de Uruguaiana (RS), para a vivência e conhecimento do Pádel. Participaram do projeto 19 alunos do quinto ano do ensino fundamental de uma escola da rede estadual de ensino do município, localizado na periferia da cidade de Uruguaiana (RS). O fator determinante na escoIha da escola foi a sua proximidade do complexo esportivo de Pádel, a receptividade da equipe diretiva da escola, bem como 
o número de alunos que o projeto poderia receber, considerando o tempo disponível para a utilização do espaço cedido e do número de monitores envolvidos. Os encontros foram mediados por uma graduanda de Educação Física e auxiliada por monitores.

As atividades com os acadêmicos de Educação Física foram desenvolvidas concomitantes ao projeto com estudantes de uma escola da rede estadual de Uruguaiana (RS). Para tanto, inicialmente entramos em contato com a equipe diretiva da escola para solicitar anuência para desenvolvimento das atividades, assim como solicitamos a autorização dos pais/responsáveis dos alunos para que eles pudessem participar do projeto.

As atividades foram desenvolvidas a partir dos seguintes métodos de ensino dos esportes: integrado e recreativo.

Para a avaliação do desenvolvimento do projeto, utilizamos os critérios de frequência e autoavaliação dos participantes a partir de rodas de conversas ao final dos encontros; e observações diretas realizadas no decorrer dos seis meses do projeto, que tiveram como objetivo diagnosticar a apropriação do Pádel pelos graduando e também pelos alunos do ensino fundamental participantes do projeto.

\section{RESULTADOS}

Uruguaiana é um município brasileiro situado na fronteira oeste do estado do Rio Grande do Sul, junto à fronteira fluvial com a Argentina e o Uruguai. Dessa maneira, convergem na cidade vários costumes e manifestações culturais oriundos de argentinos e uruguaios. Destacamos o Pádel, que tem expressividade no município. Estima-se que no ano de 2017 já haviam mais de 500 jogadores na cidade, com faixa etária variada, desde crianças até adultos.

\section{Projeto Pádel Cidadão como espaço de formação para acadêmicos do curso de Educação Física}

A iniciativa de construção do projeto surgiu de uma graduanda do curso de Educação Física com experiência na modalidade e a partir do engajamento de outros acadêmicos interessados pelo tema. O projeto foi criado e planejado junto ao GEEFE da Unipampa, onde desenvolvemos seminários para aquisição e apropriação conceitual da história e dos fundamentos técnicos da modalidade Pádel. Os encontros continuaram durante todo o percurso do projeto, com reuniões semanais, onde discutimos o andamento das ações, as dificuldades e os resultados encontrados.

Como primeira atividade prática, organizamos uma Clínica de Pádel com o professor convidado Robinson Boneberg, que atualmente ministra aulas em Madri, Espanha. No decorrer de um dia, o professor abordou os seguintes temas/fundamentos: características gerais do pádel, empunhadura continental, posicionamento do corpo, backhand e forehand. Após, as atividades do projeto foram desenvolvidas semanalmente, durante seis meses, com a sequência didática descrita no Quadro 1.

Para o desenvolvimento das atividades, adotamos o método integrado como principal suporte didático, através dos jogos situacionais e/ou condicionados. O método integrado (ou sistêmico) busca possibilitar a integração dos fundamentos técnicos e táticos em uma mesma situação/treinamento. Segundo Reverdito e Scaglia (2009), no método integrado, o ambiente e a estrutura das atividades estimulam diferentes inteligências ao mesmo tempo, pois o ensino do esporte não é desenvolvido de forma fragmentada, partes isoladas, mas como um sistema integrado. Corroborando, Freire (2003) descreve que no método integrado, o ensino das habilidades técnicas e táticas são integradas ao jogo, às situações requeridas pelo ambiente, e o que determinará o sucesso ou o insucesso dessas capacidades/ habilidades no jogo é a própria vivência e experiências do aluno nas atividades desenvolvidas.

Quadro 1. Atividades desenvolvidas no projeto Pádel Cidadão para os acadêmicos de Educação Física.

\begin{tabular}{|ll|}
\hline Mês & Fundamentos técnicos \\
\hline Agosto & Empunhadura \\
\hline Setembro & Saque do lado direito e saque do lado esquerdo \\
\hline Outubro & Golpes de forehand e golpes de backhand \\
\hline Novembro & Smash e voleio \\
\hline Dezembro & Posicionamento em quadra \\
\hline
\end{tabular}

Como estratégia para o desenvolvimento do método integrado, recorremos aos jogos situacionais, os quais, segundo Greco (1998), trabalham situações de jogo onde os discentes adquirem a habilidade de leitura de jogo ao mesmo tempo em que desenvolvem os aspectos técnicos da Pádel. Para Greco (1998), através desses jogos, é possível o desenvolvimento de aspectos técnico-motores e de coordenação associados a processos cognitivos de compreensão tática do jogo e às capacidades de percepção, antecipação e tomada de decisão.

Ao término do semestre, com o desenvolvimento e progressão das habilidades e conhecimentos sobre o Pádel, realizamos um campeonato interno entre os participantes do projeto, denominado Ranking de Pádel, comumente realizado entre jogadores de Pádel e de Tênis, que permite aos jogadores participar de uma sequência de jogos ao longo de uma temporada ou dia, alternando suas duplas, permitindo que todos joguem com todos e também contra todos. A partir de então, são estabelecidas formas de pontuação individual para que o ranqueamento aconteça.

Com o decorrer do projeto, entre os principais resultados observados, destacamos o notável interesse dos discentes em conhecer e praticar um esporte fora do eixo hegemônico (handebol, basquete, vôlei e futebol), a aquisição de conhecimentos conceituais e práticos do Pádel e os métodos de ensino da modalidade desportiva. Também, observou-se uma melhoria no convívio social, bem como, nas capacidades técnicas/táticas do Pádel.

\section{Projeto Pádel Cidadão no contexto sócioeducativo de estudantes da rede pública}

Com o resultado positivo do ensino do Pádel com os discentes de Educação Física, muitos acadêmicos tornaram-se monitores e auxiliaram nas atividades desenvolvidas com os escolares.

Na primeira atividade com os estudantes procuramos apresentar o Pádel, o ambiente e os materiais através de brincadeiras de reconhecimento da quadra, das bolas e das raquetes. Também, foram organizadas brincadeiras mobilizando a coordenação motora, com o popularmente chamado de "minhocão", 
um circuito com bambolês e cones chineses usados como obstáculos. Posteriormente foi planejada e aplicada uma sequência didática, conforme descrita no Quadro 2.

Quadro 2. Atividades desenvolvidas para os alunos da rede pública de ensino.

\begin{tabular}{|ll|}
\hline Mês & Fundamentos e Atividades \\
\hline Agosto & Reconhecimento da quadra e dos materiais através de brincadeiras. \\
\hline Setembro & $\begin{array}{l}\text { Fundamento técnico de saque com jogos de precisão, com alvos } \\
\text { colocados na quadra e localizações de posicionamento com cones } \\
\text { para receber o saque. }\end{array}$ \\
\hline Outubro & $\begin{array}{l}\text { Fundamento técnico do voleio a partir de circuitos motores e } \\
\text { exercícios em duplas. }\end{array}$ \\
\hline Novembro & $\begin{array}{l}\text { Fundamento técnico do smash com jogos de precisão, com a } \\
\text { utilização de cones como alvo. }\end{array}$ \\
\hline Dezembro & $\begin{array}{l}\text { Posicionamento em quadra delimitando a área com cones, a partir } \\
\text { de brincadeiras. }\end{array}$ \\
\hline
\end{tabular}

Como principal alicerce didático-pedagógico empregamos o método recreativo para o desenvolvimento das atividades. Segundo Tenroller e Merino (2006), o método recreativo é o mais popular na iniciação dos esportes, a adoção dele se faz presente em diferentes realidades e níveis dos esportes. Nesta linha, os professores devem apresentar uma pedagogia pautada nas capacidades de cada um, tendo como aliado o uso da criatividade, para proporcionar momentos prazerosos para a criança.

Corroborando, Paes (2001) destaca que o principal objetivo dessa metodologia é assegurar o processo ensino-aprendizagem, com valores e princípios voltados para uma atividade prazerosa e motivadora, respeitando a individualidade e o desenvolvimento infantil. Portanto, o ensino das habilidades e do desenvolvimento motor através do esporte deve ocorrer de maneira variada, de forma prazerosa, oportunizando o maior número de experiências motoras, incluindo todos os indivíduos, dando uma base para que em algum momento de suas vidas esse aluno possa se aperfeiçoar em um ou mais esporte.

Como resultados relevantes, identificamos que as crianças do projeto estavam cada dia mais motivadas e interessadas em aprender o Pádel. Notamos que a autoestima dos alunos elevou na medida em que perceberam ser capazes de praticar o Pádel, pois aos olhos dos alunos, essa modalidade estava muito longe do seu alcance, devido aos altos custos do material a ser utilizado para a prática. A esse respeito, Machado, Souza e Silva (2019) comentam que uma prática de esportes com raquete bem estruturada e planejada possibilita maior motivação e interesse dos alunos, e que a motivação, é um dos vieses que sustenta a prática esportiva.

Com isso, almejamos que estudantes da rede pública de ensino do município de Uruguaiana (RS) possam apropriar-se das habilidades dessa modalidade esportiva, propiciando à sociedade diferentes ramos de atividades de lazer e, deste modo, auxiliar na difusão e democratização do Pádel no município em foco. Para que isso aconteça, propusemos à Prefeitura Municipal de Uruguaiana a construção de uma quadra pública de Pádel no principal parque da cidade, para que todos tenham a possibilidade de praticar este esporte, independentemente de suas condições econômicas

\section{CONCLUSÃO}

Pautada nas metodologias integrada e recreativa, concluímos que o projeto Pádel Cidadão proporcionou um processo de ensino-vivência-aprendizado com ações significativas para os acadêmicos, como forma de formação profissional, e aos alunos da rede pública estadual como construção de conhecimentos e práticas da modalidade esportiva do Pádel.

O projeto também possibilitou a democratização do acesso ao esporte de Pádel aos discentes do Curso de Educação Física e aos estudantes da rede pública de ensino do município de Uruguaiana (RS), permitindo a apropriação dos conhecimentos desta modalidade esportiva e potencializando o desenvolvimento do esporte nas futuras atividades docentes dos acadêmicos. Proporcionando o aprimoramento de conhecimentos práticos e didáticos imprescindíveis para que os professores de Educação Física em formação estejam capacitados a trabalhar com o conteúdo de Pádel nas diferentes realidades educacionais onde irão inserir-se. Incrementando, assim, o desenvolvimento do Pádel nas práticas de lazer e esportivas na comunidade e o aumento do número de praticantes, obtendo uma melhoria no convívio e na integração social.

Destaca-se que o grande alcance do objetivo desse projeto dar-se-á pela sua continuidade nos anos posteriores, proporcionando ininterrupção do trabalho desenvolvido e novas oportunidades para os discentes de graduação, bem como, escolares da educação básica, assegurando novos aprendizados.

\section{REFERÊNCIAS}

COBRAPA. Confederação Brasileira de Pádel. Regras. Porto Alegre, 2017. Disponível em: <https://cobrapa.com.br/>. Acessado em: 15 de mar. de 2020.

CORRÊA, M. M. L.; FREITAS, T. C. R.; SILVA, S. A. O ensino dos esportes de raquete no ambiente escolar. Caderno de Educação Física e Esporte, Marechal Cândido Rondon, v. 17, n. 1, p. 309-16, 2019.

FREIRE, J. B. Pedagogia do futebol. Campinas: Autores Associados, 2003.

GRECO, P. J. Iniciação esportiva universal: metodologia da iniciação esportiva na escola e no clube. Belo Horizonte: UFMG, 1998.

MACHADO, M. A. de O.; SOUZA, R. R. de; SILVA, S. A. da. Esportes de raquete, motivação, divulgação e infraestrutura: influências sobre a prática. Caderno de Educação Física e Esporte, Marechal Cândido Rondon, v. 17, n. 2, p. 177-83, 2019.

PAES, R. R. Educação física escolar: o esporte como conteúdo pedagógico no ensino fundamental. Canoas: ULBRA, 2001.

REVERDITO, R. S.; SCAGLIA, A. J. Pedagogia do esporte: jogos coletivos de invasão. São Paulo: Phorte, 2009.

ROSÁRIO, L.; DARIDO, S. A sistematização dos conteúdos da educação física na escola: a perspectiva dos professores experientes. Motriz, Rio Claro, v. 11, n. 3, p. 167-78, 2005

SILVA, J. V. P.; SOUZA, L. C. L.; CALADO, K. T. O. L.; SILVA, C. B.; REVERDITO, R. S. Família dos jogos esportivos com raquetes: metodologia e procedimentos pedagógicos. Revista Brasleira de Ciência e Movimento, Btasíia, v. 25, n. 4, p. 117-127, 2017

TENROLLER, C. A.; MERINO, E. Métodos e planos para o ensino dos esportes. São Paulo: FUCAMP, 2006.

\section{AGRADECIMENTOS}

Os autores agradecem ao Complexo Esportivo Pádel do Engenho, que cedeu espaço e equipamentos para a viabilização do projeto. 


\section{CONFLITO DE INTERESSE}

Os autores do estudo declaram não haver conflito de interesses.

\section{FINANCIAMENTO}

Este estudo não contou com apoio financeiro.

\section{ORCID E E-MAIL DOS AUTORES}

Mariza de Fátima dos Santos Sanchez (Autor Correspondente) ORCID: 0000-0002-6615-3240.

E-mail: sanchezmariza567@gmail.com

Lucia Helena Rivero Meza

ORCID: 0000-0002-9340-1609.

E-mail: luciahelenariveromeza@gmail.com

Phillip Vilanova Ilha

ORCID: 0000-0002-4433-0349.

E-mail: phillip@unipampa.edu.br

Fernanda Stein

ORCID: 0000-0002-7938-9703.

E-mail: fernandastein.ef@gmail.com 